\title{
11. VELOCITY BOUNDS ON THE SEISMIC STRUCTURE OF MESOZOIC CRUST AND UPPER MANTLE IN THE SOUTHWEST PACIFIC BASIN FROM DOWNHOLE OBSERVATIONS AT DEEP SEA DRILLING PROJECT HOLE 595B ${ }^{1}$
}

\author{
R. B. Whitmarsh, J. A. Orcutt, T. H. Jordan, R. G. Adair, and P. M. Shearer, Geological Research Division, \\ Scripps Institution of Oceanography ${ }^{2}$
}

\begin{abstract}
The Marine Seismic System (MSS) was deployed during Leg 91 of the Deep Sea Drilling Project in order to assess the reduction in noise levels achievable through burying a seismic inertial sensor within the basaltic crust. The noise levels were significantly reduced and the usual coupling problems experienced by ocean bottom seismographs were essentially eliminated. This contribution reports on the results of early analyses of data collected while shooting two roughly orthogonal refraction lines. The data were processed at Scripps Institution of Oceanography and topographic corrections were applied to reduce the effects of roughness in the seafloor topography. The data were first corrected to the seafloor and the remaining correlations with topography were attenuated by a correction for the height of the seafloor above a datum. The corrections reduced traveltime scatter and significantly tightened extremal envelopes on acceptable velocity functions. The best constrained solutions were achieved over moderate topography while the presence of substantial seamounts always introduced scatter presumably due to unknown features off the ship's track. Velocity. anisotropy was discovered within the oceanic upper mantle and the velocity structure of this old crust was found to be rather "normal."
\end{abstract}

\section{INTRODUCTION}

The recent advent of digitally recording ocean-bottom seismographs (OBS) has allowed data sets with high signal-to-noise ratios and relatively broad bandwidths to be collected. However, an OBS is normally susceptible to the uncertainties of imperfect coupling via unlithified sediments of low shear strength to the solid earth (Sutton et al., 1981; Trehu, 1984) and to the multiply converted and reflected phases generated at the boundaries of the sediment layer (Lewis and McClain, 1977). These problems, which can distort and complicate the signals, are largely avoided by emplacing sensors into holes drilled in igneous basement (Layer 2) beneath the sediments. Background noise is also less downhole because of the falloff of microseismic noise with distance from the ocean/sediment interface (Adair et al., 1984). Experiments using the DSDP downhole observation technique have been reported by Stephen $(1979,1983)$, Stephen et al. (1980), Duennebier and Blackington (1983), and Duennebier et al. (1982). This chapter describes the analysis of two orthogonal unreversed refraction profiles, which exhibit an unusually good signal-to-noise ratio, obtained by recording signals from a set of downhole seismometers emplaced in DSDP Hole 595B.

The experiment described here was part of the trials of the Marine Seismic System (MSS) (Harris et al., this volume). The MSS was first emplaced in Hole 395A,

\footnotetext{
${ }^{1}$ Menard, H. W., Natland, J., Jordan, T. H., Orcutt, J. A., et al., Init. Repts. DSDP, 91: Washington (U.S. Govt. Printing Office).

2 Addresses: (Whitmarsh, present address) Institute of Oceanographic Sciences, Wormley, Godalming, Surrey GU8 SUB, England; (Orcutt, Shearer, present address) Institute of Geophysics and Planetary Physics (A-025), Scripps Institution of Oceanography, La Jolla, CA 92093, (Adair, present address: Rockwell Hanford Operations, Energy Systems Group, P.O. Box 800, Richland, WA 99352); (Jordan, present address) Department of Earth, Atmospheric, and Planetary Sciences, Massachusetts Institute of Technology, Cambridge, MA 02139.
}

Leg 78B, in the central North Atlantic Ocean in March 1981 (Hyndman, Salisbury, et al., 1984; Adair et al., 1984). Further trials were conducted during Leg 91 in the southwest Pacific Basin in January-February 1983. As part of these trials, two refraction profiles were fired by the Melville and recorded by the MSS aboard Glomar Challenger; the preliminary results of these profiles are reported here. This chapter does not take into account the more voluminous but noisier set of data recorded concurrently by four digital OBSs (Moore et al., 1981) within $0.4 \mathrm{~km}$ of Hole 595B (Shearer et al., this volume).

\section{REGIONAL SETTING}

The experiment was conducted in the southwest $\mathrm{Pa}$ cific Basin about $1000 \mathrm{~km}$ east of the Tonga Trench and $1800 \mathrm{~km}$ west-southwest of Tahiti (Fig. 1, inset). This is a remote, poorly surveyed and little known region. At the time of the experiment, no clear indication of the direction of spreading centers and fracture zones was available from magnetic anomalies. From a knowledge of the regional depth (about $5600 \mathrm{~m}$ ) and of the history of adjacent portions of the Pacific Ocean, it was inferred only that the lithosphere at Site 595 had been produced at a fast-spreading ridge at high southern latitude sometime during the Mesozoic. The geoid calculated from satellite altimetry suggested that there were no substantial bathymetric or tectonic features in the immediate area (Sandwell, 1984; Dixon and Parke, 1983).

Subsequently, an analysis of magnetic anomalies and other information has suggested the existence of $050^{\circ}$ trending seafloor spreading magnetic anomalies $(\mathrm{H}$. W. Menard, personal communication, 1983). Soundings compiled within about a $2^{\circ}$ square enclosing the site indicate the existence of ridges and troughs with a similar trend. However, a roughly north-south to north-northwest ar- 


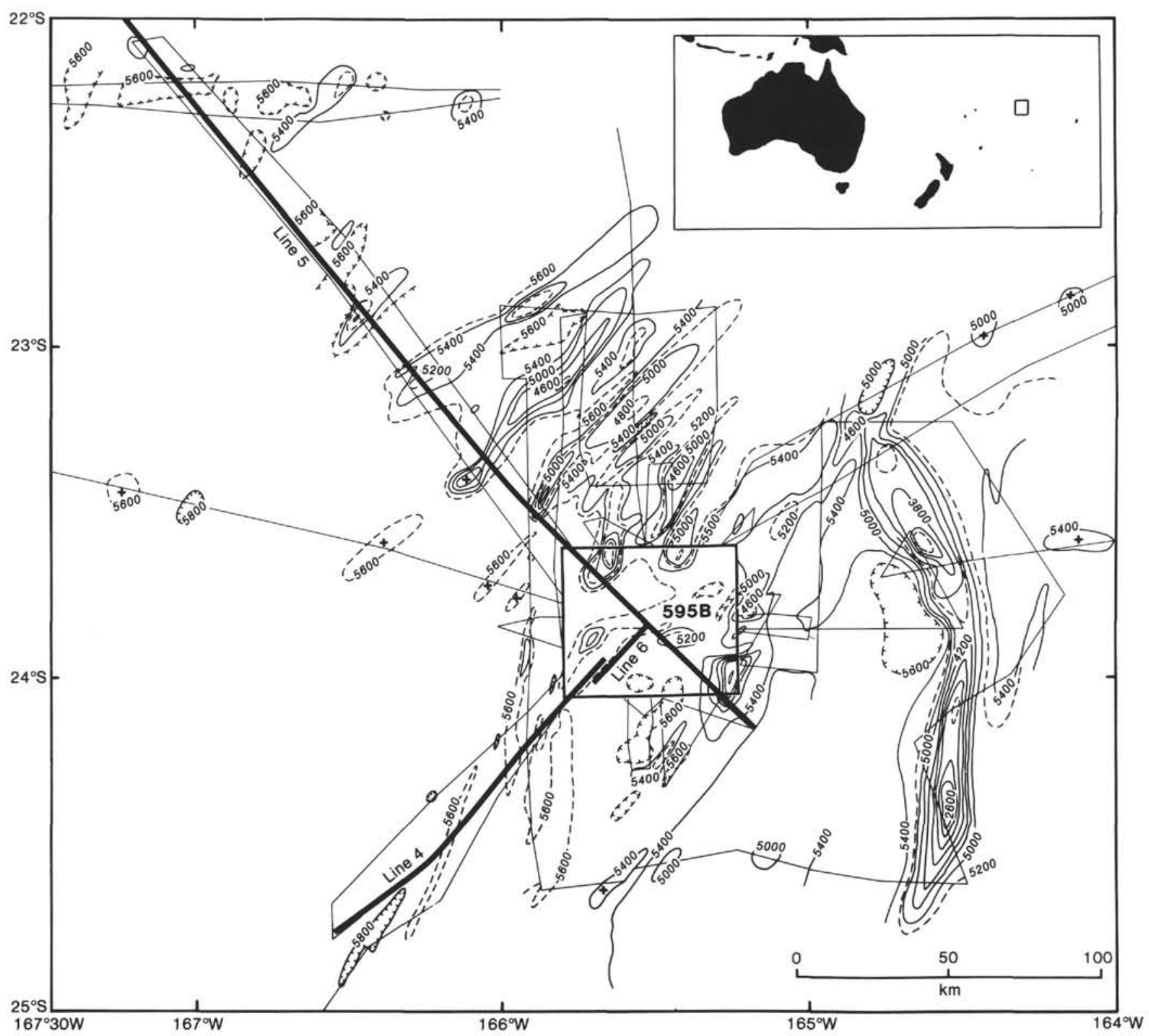

Figure 1. Bathymetry and locations of Lines 4, 5, and 6 around Site 595 in the southwest Pacific Basin (see inset). Fine lines denote available sounding tracks; tracks were too dense to be shown clearly within the box. Contour interval is $400 \mathrm{~m}$ (solid lines) or $200 \mathrm{~m}$ (dashed lines).

cuate high-ridge feature is also well delineated about $100 \mathrm{~km}$ to the east (Fig. 1).

Scant seismic reflection profiles from passage tracks of Conrad 17 and Eltanin 40, augmented by data from the Melville and the Glomar Challenger, indicate unusually thin sediments that are at least $0.05-0.10 \mathrm{~s}$ thick in the vicinity of Hole 595B. Sediment thicknesses are difficult to determine accurately, however, because of the ubiquitous occurrence of a very strong, presumably intrasediment, reflector concordant with the seabed that obscures the sediment/basement reflection. The Shipboard Scientific Party (this volume) measured seismic velocities of $1.46-1.54 \mathrm{~km} / \mathrm{s}$ on the cores of brown pelagic clay from Site 595 .

The sediment was $70 \mathrm{~m}$ thick in Holes 595A and 595B. Cretaceous radiolarians were found at a depth of approximately $40 \mathrm{~m}$, but because of the nature of the sedi- ments, the recovery of fossils from greater depths was poor. The sediment/basement contact was not recovered, and paleontological ages for this horizon are simply not available. An analysis of seafloor spreading magnetic anomalies near the site indicates a crustal age considerably older than the Cretaceous quiet zone and within the Mesozoic magnetic anomaly sequence $(\mathrm{H}$. W. Menard, personal communication, 1983). An earlier analysis of local magnetic anomalies placed the site at Anomaly M-29 with an age of 157 Ma on the scale of Cande et al. (1978), although the interpretation is very tentative. The crust is, nevertheless, some of the oldest yet sampled in the Pacific Ocean and may be as old as Late Jurassic.

\section{THE EXPERIMENT}

The objectives of the seismic refraction experiment were to investigate the crust and upper mantle structure 
of old lithosphere and to determine, by a pattern of radiating lines centered on the borehole, the direction and extent of upper mantle anisotropy. The experiment was constrained by the rate of progress of the MSS trials. Loss of time caused by equipment malfunction allowed the shipboard recording of just two orthogonal refraction lines. The first, Line 4 (including some fill-in shots of Line 6) extended about $150 \mathrm{~km}$ southwest of the hole. The second, Line 5, was a split profile $50 \mathrm{~km}$ long to the southeast and $260 \mathrm{~km}$ long to the northwest (Fig. 1).

The shots were fired by Melville. Within $30 \mathrm{~km}$ of the site, 1-, 2-, or 3-lb. charges of DuPont heavy-duty primers, suspended from floats at $10-\mathrm{m}$ depth, were used. In the immediate vicinity of the Glomar Challenger the floats were dispensed with and these charges detonated at a depth of $46 \pm 2 \mathrm{~m}$. These small shots were fired about every $300 \mathrm{~m}$. A second type of shot consisted of $13.6-136-\mathrm{kg}$ charges of Tovex.

The seismic signals were detected by the borehole instrumentation package (BIP) of the MSS, a $10.5-\mathrm{m}$-long, 0.2 -m-wide cylinder. This was emplaced at the bottom of Hole 595B, which had been drilled to a depth of $124 \mathrm{~m}$ beneath the seafloor and $54 \mathrm{~m}$ into Layer 2 . Because of technical problems, the BIP was not clamped to the wall rock. In view of the rigidity of the basalt at the bottom of the hole and the large mass (1.2 tons) of the BIP resting on a small area (up to $0.03 \mathrm{~m}^{2}$ ) at its base, it is estimated that at frequencies of under $10 \mathrm{~Hz}$ the BIP followed the vertical motion of the wall rock without distortion (Sutton et al., 1981; White, 1983). The sensors were three orthogonal broad-band Teledyne Geotech Inc. S750 accelerometers with one sensor vertical. There was no device to orient the horizontal sensors.

After bandpass filtering (Fig. 2), the signals were digitized and passed up an electromechanical cable to the Glomar Challenger where they were recorded at 40 samples/s/channel. Because of the appearance of strong instrumental noise on one of the horizontal seismometers

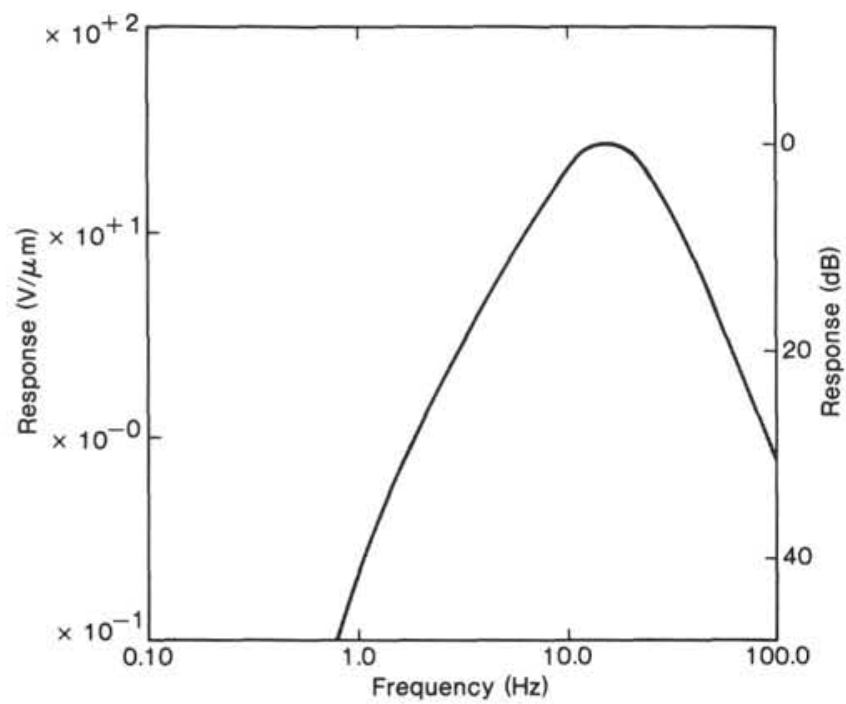

Figure 2. Displacement response of the short-period channels of the MSS. shortly after emplacement, data from only the vertical and from one horizontal seismometer were available for analysis (only data from the vertical seismometer are presented here).

A near-surface hydrophone was also deployed from the Glomar Challenger at a depth of $10 \mathrm{~m}$ to record the relatively high-frequency water waves from the explosions. This was necessary for the accurate determination of shotto-receiver ranges.

Timing was with respect to a local clock on each ship that was checked regularly against radio time signals from Station WWVH.

\section{DATA REDUCTION}

A sound-velocity/depth profile (Table 1) was constructed, on the basis of temperature and salinity observations made during the experiment down to $1000 \mathrm{~m}$ and from observations made $500 \mathrm{~km}$ away by Stommel et al. (1973) to $5400 \mathrm{~m}$ in June-July 1967, using the equation of Clay and Medwin (1977). This profile was used to calculate shot-to-borehole ranges from the water-wave traveltimes of mainly bottom reflected phases detected by the nearsurface hydrophone. These ranges included a correction for the offset of the Glomar Challenger from the borehole using the precise $( \pm 15 \mathrm{~m})$ measurements provided by the ship's dynamic positioning system. Ranges calculated by this method were consistent within $\pm 80 \mathrm{~m}$ with ranges based on water waves detected by the OBS hydrophones. At ranges in excess of about $90 \mathrm{~km}$ the signals at the surface hydrophone were too weak. Instead, the arrival time on the vertical seismometer of a probable tube wave, generated by the arrival of the water wave at the top of the hole, was used after correction for an estimated downhole propagation time of $0.09 \mathrm{~s}$.

To minimize the scatter in arrival times of several tenths of a second caused by the varying water depth under the shots (Fig. 3) the water-path correction used by Spudich and Orcutt (1980), and described in detail by Purdy (1982), was applied. This modifies traveltimes and ranges to those applicable to a source situated at the point of entry into the seabed of the ray setting off from each actual shot. A horizontal phase-velocity/range function must be known or assumed with this method, and this was determined from a cubic spline fitted to all the time-distance data for each line segment. The tightness of fit of the spline was chosen subjectively to be the smoothest that seemed to fit the general trends in the data. Most time and distance corrections were less than about $3.9 \mathrm{~s}$

Table 1. Sound-speed/ depth model.

\begin{tabular}{rc}
\hline $\begin{array}{c}\text { Depth } \\
(\mathrm{m})\end{array}$ & $\begin{array}{c}\text { Sound speed } \\
(\mathrm{m} / \mathrm{s})\end{array}$ \\
\hline 0 & 1535.5 \\
380 & 1513.0 \\
630 & 1488.7 \\
1000 & 1484.3 \\
1500 & 1484.3 \\
3910 & 1519.6 \\
6000 & 1553.1 \\
\hline
\end{tabular}



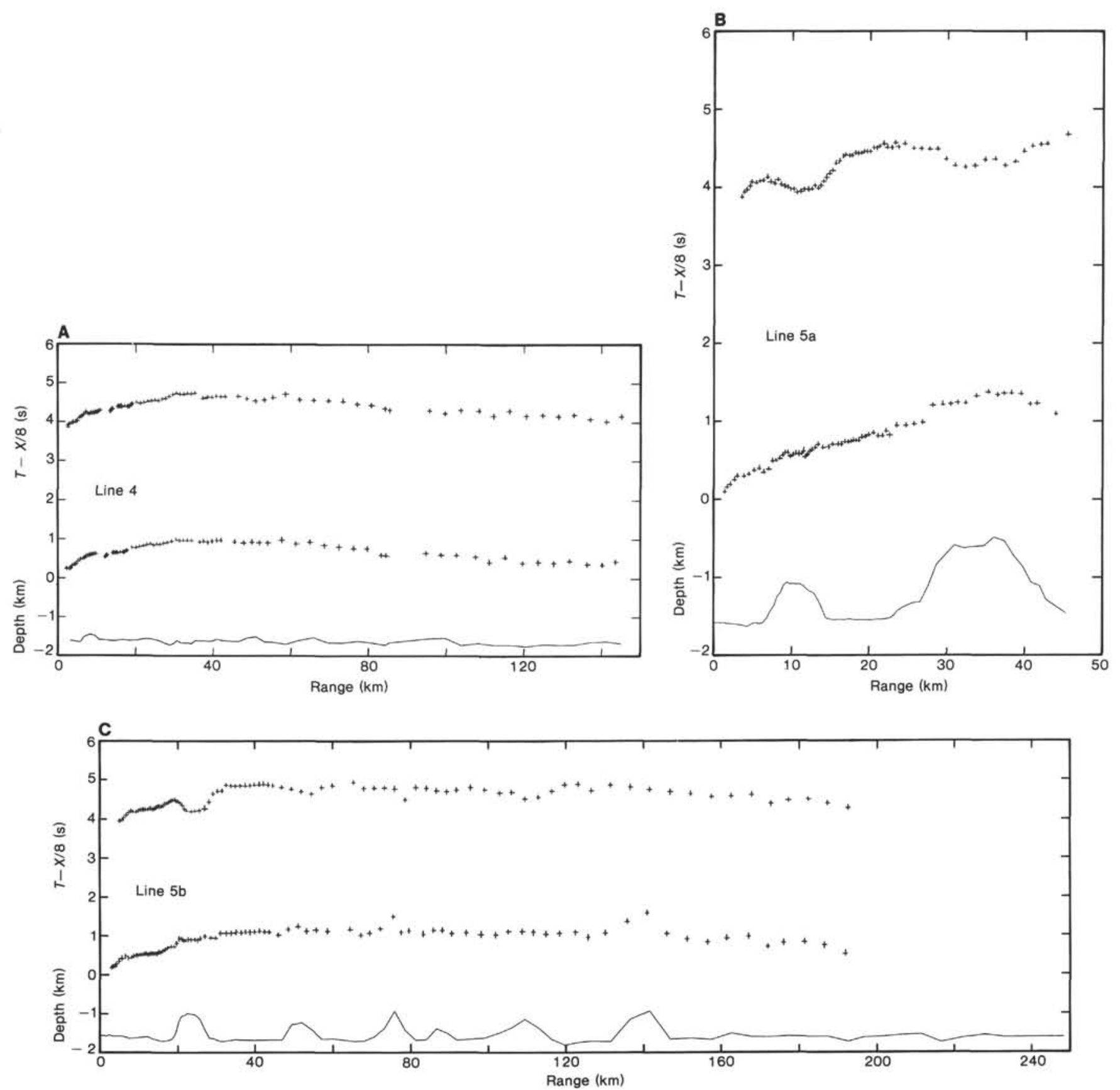

Figure 3. First-arrival picks (reduced to $8 \mathrm{~km} / \mathrm{s}$ ) before and after application of the water-path and $d t / d h$ corrections (upper and lower curves, respectively) plotted above bathymetry along each profile. A. Line 4; B. Line 5a; C. Line 5 b.

and $1.3 \mathrm{~km}$, respectively. The appreciable decrease in traveltime scatter achievable by this technique is shown in Figure 3.

Nevertheless, even after applying the water-path correction, a systematic correlation between traveltimes and the depths of the ray entry point is apparent. For each line the depth residual with respect to the mean alongprofile depth and residual of the water-path-corrected traveltimes, from a second spline fitted to the time-distance data, were plotted. Least-squares linear regression on a compilation of all such depth and time residuals gave highly significant (more than $99 \%$ ) correlation coefficients of -0.41 and -0.47 for crustal and mantle arrivals, respectively. The associated regression coefficients, which we shall call $d t / d h$, were -0.11 and $-0.18 \mathrm{~s} / \mathrm{km}$, respectively. These values fall within the ranges of -0.09 to -0.11 and -0.15 to $-0.19 \mathrm{~s} / \mathrm{km}$ found by White and Purdy (1983) for a larger data set of lower crustal and upper mantle arrivals, respectively. White and Whitmarsh (1984) determined $d t / d h$ values of -0.10 and $-0.14 \mathrm{~s} / \mathrm{km}$ for the upper and lower crust, respectively.

The significance of our correlation coefficients and the consistency between $d t / d h$ values from three different data sets indicate a genuine systematic relationship. White and Purdy (1983), on the basis of ray-tracing ex- 
periments, believed the relationship was caused by deeper and deeper isovelocity surfaces becoming more and more planar. Therefore, we applied a second correction, equivalent to our appropriate regression coefficient, to the traveltimes to remove the linear correlation between time and bathymetry so as to obtain the smoothest possible set of time-distance data prior to the application of $\tau-p$ analysis. This correction involved no adjustment of distance since it is assumed, over a given distance range, that the regression coefficient is independent of distance. The datum chosen to apply the $d t / d h$ correction was $5740 \mathrm{~m}$, the depth of the BIP. It was further assumed that $75 \mathrm{~m}$ of $1.5 \mathrm{~km} / \mathrm{s}$ sediment lay under all shot points (there were no reflection profiles along the shooting tracks), and a small time correction was applied to remove the effect of this layer.

Finally, record sections of the three profile segments were plotted using ranges and time adjusted by the previous procedures (Fig. 4). There are differences and similarities between the three observed record sections. The Line 4 section has an excellent signal-to-noise ratio and many first arrival onsets can be picked to within $\pm 0.05 \mathrm{~s}$ or better even beyond $100 \mathrm{~km}$. Weak lower crust arrivals between 20 and $30 \mathrm{~km}$ are followed by strong Moho reflections. At greater ranges there are unusual strong lowfrequency secondary arrivals to just beyond $130 \mathrm{~km}$ that crudely fall on a $6.8 \mathrm{~km} / \mathrm{s}$ slope, but, in detail, segments with phase velocities as high as $7.2 \mathrm{~km} / \mathrm{s}$ can be distinguished. The mantle first arrivals maintain a fairly constant amplitude, but exhibit quite marked variations in high-frequency content (compare 40-65 km with 68$84 \mathrm{~km})$.

Line 5 was shot over a rougher seafloor than Line 4 , and the effects of focusing and defocusing near seafloor elevations manifest themselves as rapid trace-to-trace amplitude changes (e.g., on Line $5 \mathrm{a}, 7-13 \mathrm{~km}$ and beyond $24 \mathrm{~km}$; on Line $5 \mathrm{~b}, 19-27 \mathrm{~km}, 110-111 \mathrm{~km})$. The signalto-noise ratio is again excellent out to about $150 \mathrm{~km}$. Most arrivals could be picked to $\pm 0.04 \mathrm{~s}$ or better. Between 150 and $260 \mathrm{~km}$ the Line $5 \mathrm{~b}$ first arrivals become increasingly hard to pick and for the last $70 \mathrm{~km}$ of the profile cannot be picked with any confidence. This was due in part to an increased noise level caused by a series of earthquakes probably originating in the Tonga-Kermadec Trench region. Again, weak lower crustal first arrivals are evident. Unlike Line 4, strong low-frequency secondary arrivals are not seen between 40 and $130 \mathrm{~km}$. The crust-mantle triplication is also less clear on Lines $5 \mathrm{a}$ and $5 \mathrm{~b}$. The mantle first arrivals exhibit trace-to-trace variations in high-frequency content similar to Line 4, but they seem to be less systematic.

These features will be accounted for eventually when full waveform modeling of the observed record sections has been completed.

A compilation of the corrected first-arrival traveltimes from both profiles (Fig. 5) shows that all times out to $28 \mathrm{~km}$ fall within a narrow \pm 0.07 -s band suggesting only limited lateral variation in structure in all but the lowermost crust. Conversely, the upper mantle intercept time of Line 4 is about $0.4 \mathrm{~s}$ smaller than that of Line 5; such a large difference suggests a thinner crust. Lastly, the in- creasingly earlier mantle arrivals seen as range increases along Line 4 suggest higher velocity uppermost mantle material under that profile.

For the initial analysis of our data, we chose to carry out a joint $(x-p)$ and $(\tau-p)$ linear extremal inversion, based on traveltimes, in order to obtain bounds outside which no velocity-depth model should lie (Orcutt, 1980). This procedure assumes a laterally homogeneous earth. Spudich and Orcutt (1980) discussed the disproportionately large effect of a small number of bad observations on the calculated bounds. As explained earlier, we took considerable care to correct the observed $(X, T)$ points not only for the varying water path but also for the well-established correlation of the traveltime residuals and depth residuals. Application of the $d t / d h$ correction, where $d h$ is relative to a horizontal datum, has the effect of "flattening" the seabed. Any remaining scatter in arrival times must represent the effect of nonhorizontal (undulating) isovelocity surfaces, real lateral velocity variations, or observational errors (including poorly known bathymetry and sediment thickness under the shots).

Stephen and Harding (1983) have noted that borehole observations give rise to an inflection in the traveltime curve, the inverse slope of which corresponds to the velocity at the receiver. However, this inflection point is expected to occur at ranges of less than $3 \mathrm{~km}$ (about $1 \mathrm{~km}$ corrected range) for the MSS observations. The few points apparently affected by this phenomenon were excluded from the inversion. Our shot spacing was not sufficiently small to accurately predict the velocity at the BIP. Most measurements during Leg 91 on basalt cores gave velocities in the range 4.4-5.2 $\mathrm{km} / \mathrm{s}$ (Shipboard Scientific Party, this volume).

The joint extremal inversion proceeded in steps. The first stage was to assign an uncertainty (typically in the range \pm 0.01 to \pm 0.04 s) to each arrival-time pick. Upper and lower bounds to the arrival times were then picked in time, distance $(T, X)$ space by selecting a small number of straight lines arranged to form the smallest possible envelope enclosing all the data (the $x-p$ functions). The corresponding $\tau-p$ points (one for each straight line in $(T, X)$ space) then formed the input to the initial joint extremal inversion. This inversion disregarded clear evidence for triplications and therefore gave bounds that varied smoothly with depth (Fig. 6, dotted line). In reality, there is a clear triplication in the record sections caused by the crust-mantle transition. The existence of such a triplication was introduced as a further constraint in the inversion procedure, first, by estimating the $(T, X)$ bounds on the lower-crust/mantle crossover point and then by introducing, in addition, estimated bounds on the location of the Moho reflection/upper mantle refraction cusp. The appropriate critical distance cannot be easily identified on record sections (Cerveny et al., 1977), and an overestimate by several kilometers was probably made. Smaller errors in the location of triplication cusps will also exist on record sections where the water-path correction has been applied to the traces. These errors (typically $0.24 \mathrm{~km}, 0.05 \mathrm{~s}$ for the mantle critical point) are caused by using a ray parameter appropriate not to the cusp but to the nearby first arrivals. Thus, the introduc- 

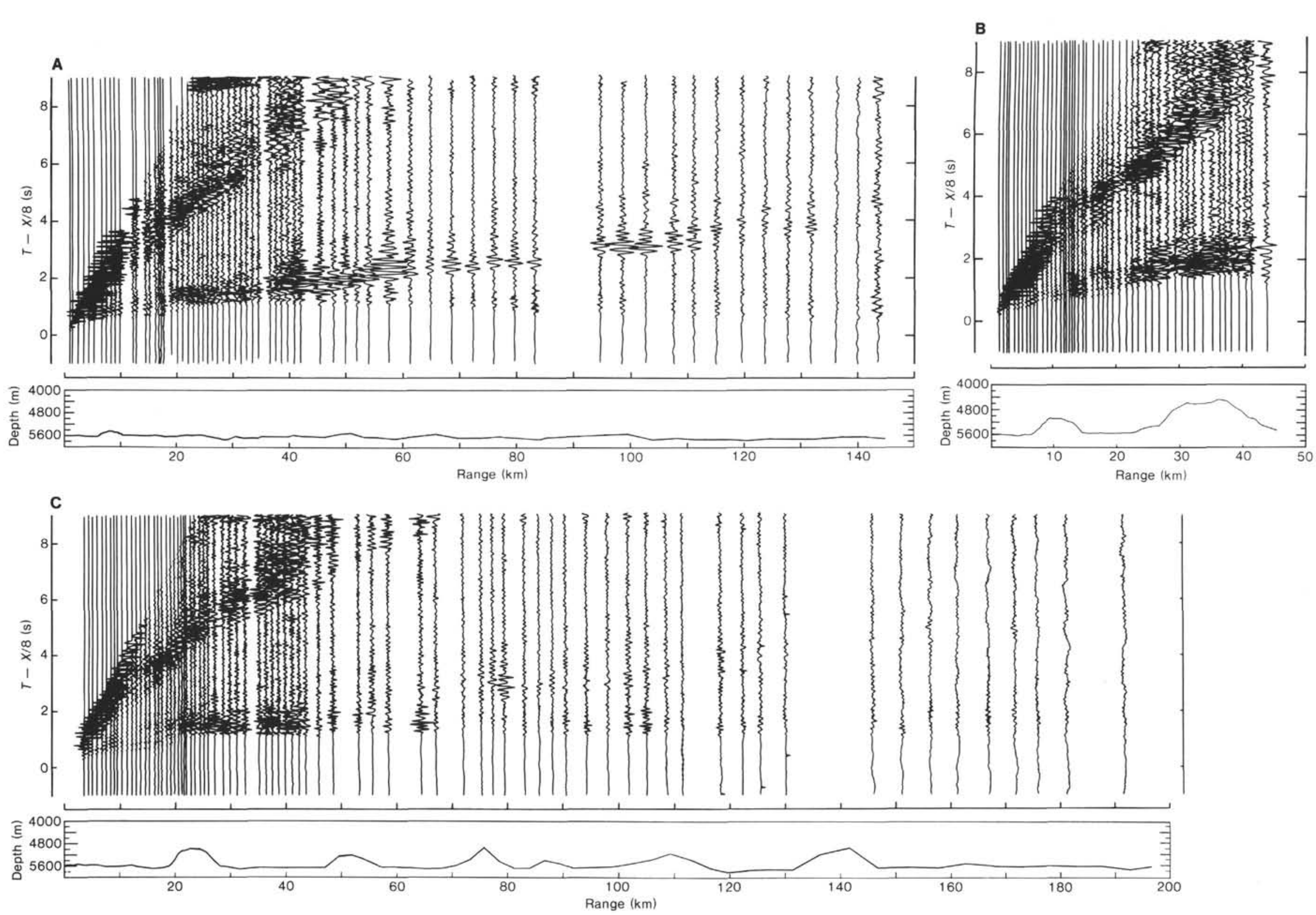

Figure 4. Unfiltered record sections (reduced to $8 \mathrm{~km} / \mathrm{s}$ ) after application of water-path and $d t / d h$ corrections. Selected traces are from the short-period vertical seismometer. A. Line 4; B. Line 5a; C. Line $5 b$. 


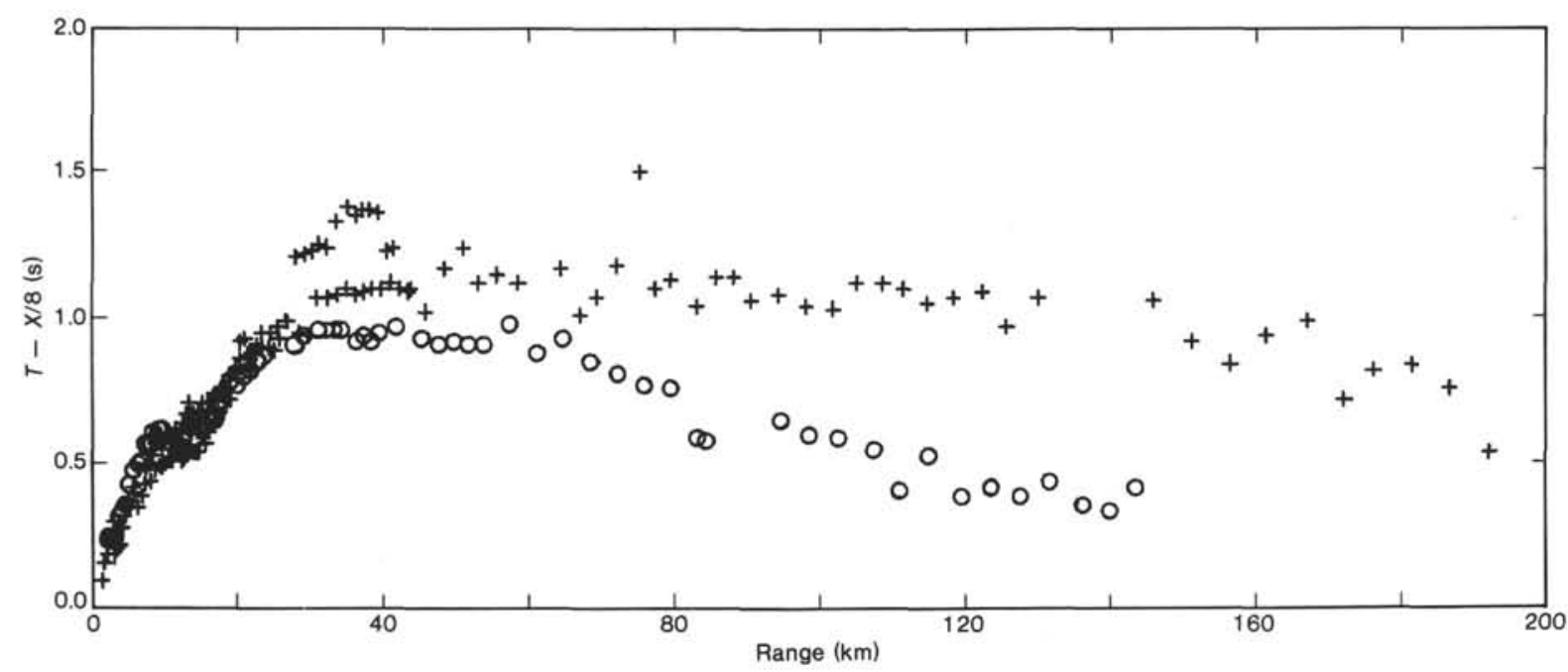

Figure 5. Combined corrected first arrival traveltime picks (reduced to $8 \mathrm{~km} / \mathrm{s}$ from Lines $4(+)$ and $5(0)$ to illustrate the differences in upper mantle arrival times.

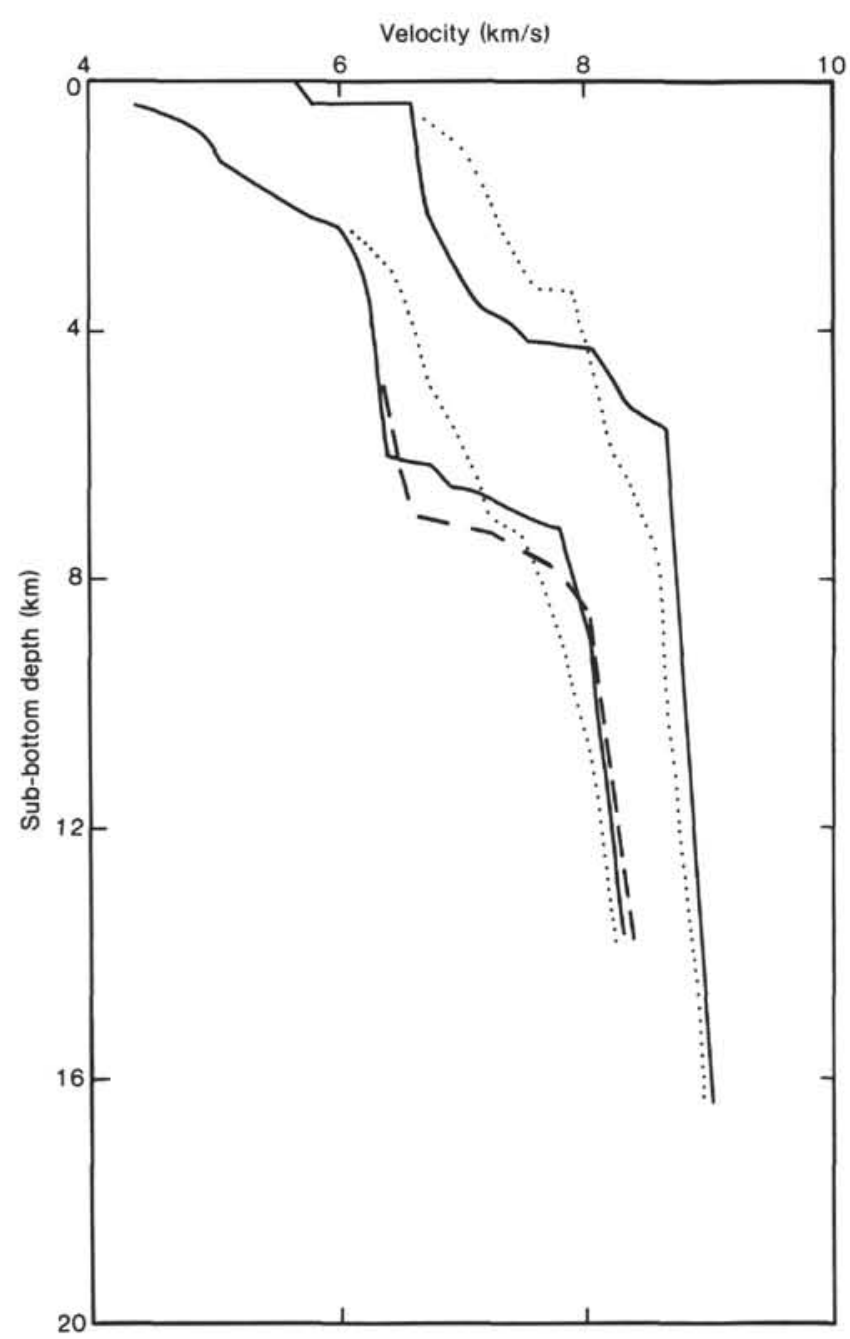

Figure 6. Extremal bounds obtained from Line 4 based on (a) first arrival times alone (dotted line); (b) first arrival times plus an estimate of the lower crust/upper mantle crossover point (dashed line, only shown where different from c); (c) as (b) plus an estimate of the mantle reflection-refraction cusp (solid line). tion of the crossover constraint tightened the extremal bounds substantially (Fig. 6, dashed line); only a slight improvement was achieved by also using the cusp constraint due to the uncertainties in locating it (Fig. 6, solid line).

The combined results of the extremal inversions are given in Figure 7. The bounds only provide quite broad constraints on possible velocity-depth models in spite of the carefully corrected traveltimes caused by the scatter in these times. Inspection of Figure 3 reveals that the most scattered traveltimes along Line 5 are associated with highs in the bathymetric profiles. The combination of the shooting track not always being directed precisely away from the MSS and rapid unknown depth changes normal to this track probably made a significant contribution to this scatter. It is notable that the velocity bounds for the main crustal layer of Line 4, which experienced a total relief of only about $250 \mathrm{~m}$, are significantly narrower than those of Line 5, which experienced over four times as much relief.

In summary, Figure 7 indicates a normal oceanic crustal structure at Site 595; a 5.5-9-km-thick crust overlies upper mantle material with a velocity of at least $8.0 \mathrm{~km} / \mathrm{s}$. Greater resolution of the structure will only be achieved when synthetic seismogram modeling has been completed.

\section{ACKNOWLEDGMENTS}

We thank Captain Sid Shuman and his crew, the Deep Sea Drilling Project personnel, and in particular the engineers from Global Marine, Teledyne-Geotech, Gould, Inc., and the Naval Ocean Research and Development Activity whose unstinting efforts at sea enabled the data reported here to be collected. R. B. W. gratefully acknowledges assistance from Scripps Institution of Oceanography (SIO) and the U.K. Natural Environment Research Council, which enabled him to work on the MSS data at SIO.

\section{REFERENCES}

Adair, R. G., Orcutt, J. A., and Jordan, T. H., 1984. Analysis of ambient seismic noise recorded by downhole and ocean-bottom seismometers on Deep Sea Drilling Project Leg 78B. In Hyndman, R., Salisbury, M., et al., Init. Repts. DSDP, 78: Washington (U.S. Govt. Printing Office), 767-782. 
Cande, S. C., Larson, R. L., and La Brecque, J. L., 1978. Magnetic lineations in the Pacific Jurassic quiet zone. Earth Planet. Sci. Lett., 41:434-440.

Cerveny, V., Molotov, I. A., and Psencik, I., 1977. Ray Method in Seismology: Praha, (Univerzita Karlova).

Clay, C. S., and Medwin, H., 1977. Acoustical Oceanography: Principles and Applications: New York (John Wiley and Sons).

Dixon, T. H., and Parke, M. E., 1983. Bathymetry estimates in the southern oceans from Seasat altimetry. Nature, 304:406-411.

Duennebier, F., Stephen, R., Gettrust, J., Harris, D., Avedik, F., Pascal, G., Inderbitzen, A., Bibee, D., Fehler, M., Ballard, J. A., and Jacobsen, R., 1982. OSS IV: the results of the downhole seismometer experiment, DSDP Leg 88. EOS, 63:1025. (Abstract).

Duennebier, F. K., and Blackington, G., 1983. The ocean sub-bottom seismometer. In Geyer, R. A. (Ed.), CRC Handbook of Geophysical Exploration at Sea: Boca Raton, Florida (CRC Press Inc.), pp. 317-332.

Hyndman, R., Salisbury, M., et al., 1984. Init. Repts. DSDP, 78B: Washington (U.S. Govt. Printing Office).

Lewis, B. T. R., and McClain, J., 1977. Converted shear waves as seen by ocean-bottom seismometers and surface buoys. Seismol. Soc. Am. Bull., 67:1291-1302.

Moore, R. D., Dorman, L. M., Chin-Yen, H., and Berliner, D. L., 1981. An ocean-bottom microprocessor-based seismometer. Mar. Geophys. Res., 4:451-477.

Orcutt, J. A., 1980. Joint linear, extremal inversion of seismic kinematic data. J. Geophys. Res., 85:2649-2660.

Purdy, G. M., 1982. The correction for the travel time effects of seafloor topography in the interpretation of marine seismic data. $J$. Geophys. Res., 87:8389-8396.

Sandwell, D. T., 1984. A detailed view of the South Pacific geoid from satellite altimetry. J. Geophys. Res., 89:1089-1104.

Spudich, P., and Orcutt, J., 1980. Petrology and porosity of an oceanic crustal site: results from wave-form modeling of seismic refraction data. J. Geophys. Res., 85:1409-1433.

Stephen, R. A., 1979. The oblique seismic experiment in oceanic crust, equipment and technique. Mar. Geophys. Res., 4:213-226.

1983. The oblique seismic experiment on Deep Sea Drilling Project Leg 70. In Cann, J. R., Langseth, M. G., Honnorez, J., Von Herzen, R. P., White., S. M., et al., Init. Repts. DSDP, 69: Washington (U.S. Govt. Printing Office), 301-308.

Stephen, R. A., and Harding, A. J., 1983. Traveltime analysis of borehole seismic data. J. Geophys. Res., 88:8289-8298.

Stephen, R. A., Louden, K. E., and Matthews, D. H., 1980. The oblique seismic experiment on DSDP, Leg 52. Geophys. J. R. Astron. Soc., 60:289-300.

Stommel, H., Stroup, E. D., Reid, J. L., and Warren, B. A., 1973. Transpacific hydrographic sections at Lats. $43^{\circ} \mathrm{S}$ and $28^{\circ} \mathrm{S}$ : the SCORPIO Expedition-I: Preface. Deep-Sea Res., 20:1-7.

Sutton, G. H., Duennebier, F. K., and Iwatake, B., 1981. Coupling of ocean-bottom seismometers to soft bottom. Mar. Geophys. Res., 5:35-51.

Trehu, A. M., 1984. Lateral velocity variations in the Orozco Transform Fault inferred from observed incident angles and azimuths of P waves. Geophys. J. R. Astron. Soc., 77:711-728.

White, J. E., 1983. Underground Sound-Application of Seismic Waves: New York (Elsevier).
White, R. S., and Purdy, G. M., 1983. Crustal velocity structure on the flanks of the Mid-Atlantic Ridge at $24^{\circ}$ N. Geophys. J. R. Astron. Soc., 75:361-386.

White, R. S., and Whitmarsh, R. B., 1984. An investigation of seismic anisotropy due to cracks in the upper crust at $45^{\circ} \mathrm{N}$, Mid-Atlantic Ridge. Geophys. J. R. Astron. Soc., 79:439-467.

Date of Initial Receipt: 6 August 1984 Date of Acceptance: 29 August 1985

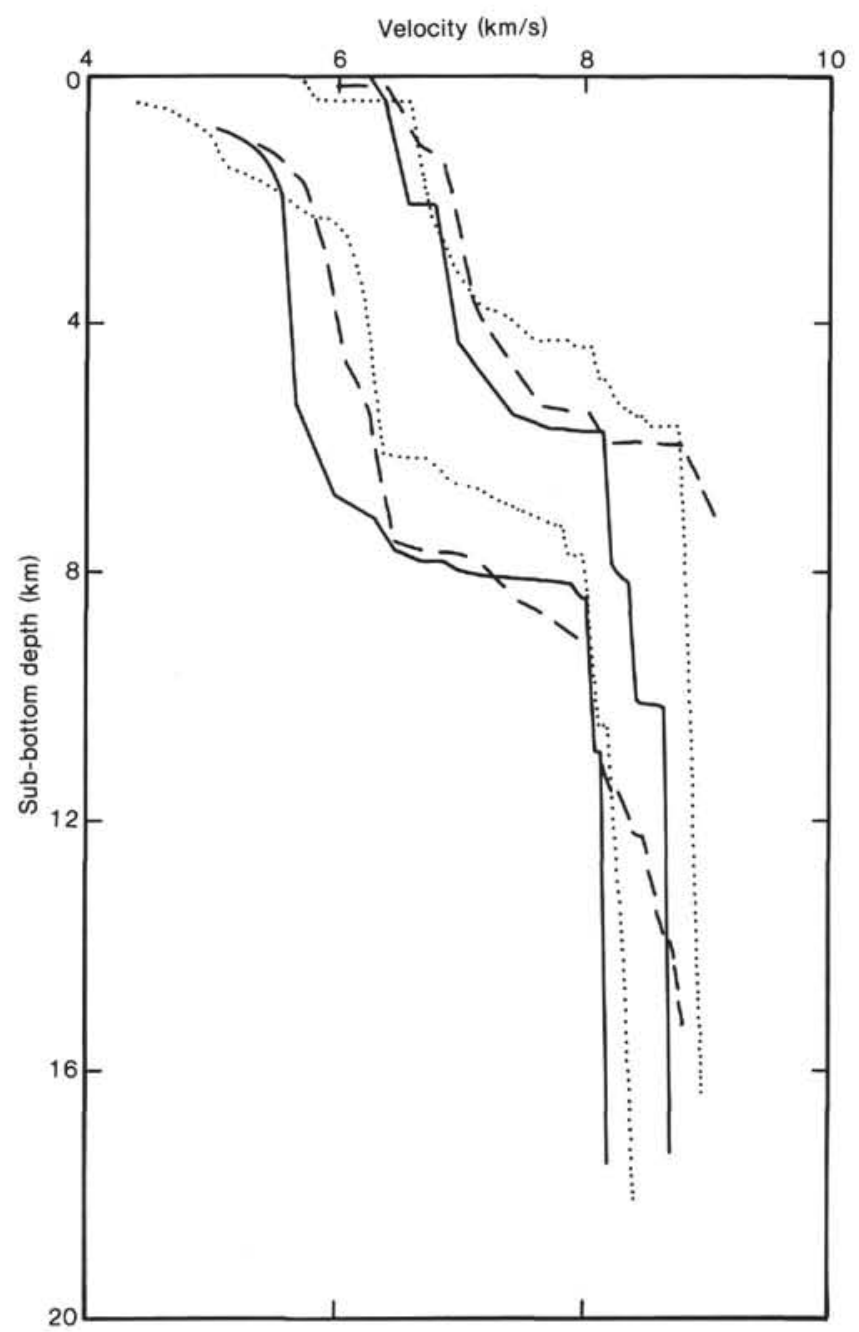

Figure 7. The results of joint linear extremal $\tau-p$ analysis on Lines 4 (dotted line), 5a (dashed line), and $5 \mathrm{~b}$ (continuous line). 